Article

\title{
A Geosimulation Approach for Data Scarce Environments: Modeling Dynamics of Forest Insect Infestation across Different Landscapes
}

\author{
Taylor Anderson ${ }^{*}{ }^{\dagger}$ and Suzana Dragicevic ${ }^{\dagger}$ \\ Spatial and Modeling Laboratory, Department of Geography, Simon Fraser University, 8888 University Drive, \\ Burnaby, BC V5A 1S6, Canada; suzanad@sfu.ca \\ * Correspondence: taylora@sfu.ca; Tel.: +1-778-782-4621; Fax: +1-778-782-5841 \\ + These authors contributed equally to this work. \\ Academic Editors: Songnian Li and Wolfgang Kainz \\ Received: 30 November 2015; Accepted: 22 January 2016; Published: 2 February 2016
}

\begin{abstract}
Insect infestation behaves as a complex system, characterized by non-linear spatial dynamics and emergent patterns that evolve from smaller to larger spatial scales. The emerald ash borer (EAB) is an invasive species that has infested and killed millions of ash trees across North America. Existing EAB models use traditional statistical approaches that often cannot address the spatiotemporal complexity emerging from EAB infestation processes. Moreover, these studies of insect infestation are limited by a lack of sufficient time series data. The objective of this study is to develop a geosimulation approach to overcome the challenge of data scarcity and represent EAB infestation at a regional scale. Geographic information systems (GIS), multi-criteria evaluation (MCE), and cellular automata (CA) are used to model EAB spread across different hypothetical landscape types. Simulation results represent EAB propagation and indicate different dynamics of spread for each landscape. Urban environments are identified as being at the greatest risk to the infestation. The proposed approach offers a theoretical framework and a modeling tool to represent the propagation of EAB infestation that can be applied with real geospatial datasets and potentially used in forest management strategies.
\end{abstract}

Keywords: cellular automata; geosimulation; geographic information systems; insect infestation; emerald ash borer; ecological modeling; data scarcity

\section{Introduction}

Geosimulation modeling approaches can be used to develop tools to better understand complex spatiotemporal phenomena such as forest insect infestation dynamics. The nature of forest insect infestation dynamics can be characterized across a variety of spatial and temporal scales and exhibit behavior of complex nonlinear systems. The full analysis and representation of the dynamics of propagation of forest insect infestations is limited due to the unavailability of empirical data that can cover adequate spatial and temporal extents. For example, in order to mitigate ecological, economic, and social impacts as quickly as possible, many management strategies require that infested trees are removed from the landscape, inhibiting the ability to collect large-scale spatial data that characterizes patterns of spread over long periods of time. Data scarcity in particular can be very limiting in model creation and testing [1]. Traditional statistical modeling methods which use top-down approaches for representing dispersal rely on large-scale empirical datasets [2-4]. Moreover, these approaches do not necessarily address the nonlinear complexity of the insect behavior. Recent geographic representations of insect infestation, such as spatially explicit models using geographic information systems (GIS), generate static spatial representations and are unable to capture spatiotemporal processes, spatial 
dynamics, and change [5]. Geosimulation modeling approaches can be very useful in representing spatiotemporal phenomena such as insect infestation due to their capability of incorporating complexity inherent to these types of systems. Furthermore, these developed approaches can provide useful tools that can be used in forecasting how insect infestation outbreaks respond in application to various scenarios. Therefore, exploring these approaches capable of overcoming these challenges would be useful [6].

Since its invasion in Michigan in 1997, the emerald ash borer (Agrilus planipennis; EAB), an exotic-invasive species native to Southeast Asia, has infested and killed millions ash trees (Fraxinus sp.) across Northeastern United States, Ontario, and Quebec [7-10]. The beetle targets common species of ash trees native to North America such as green ash (F. pennsylvannica), black ash (F. nigra), and white ash (F. americana) whereby larvae feed on the interior of the ash, creating a girdling effect that disrupts the flow of water and nutrients essential to its survival $[7,8]$. Trees infested with EAB may die in three to five years [11]. Detection of infestation is often delayed as external symptoms such as the characteristic D-shaped exit holes, chlorosis, crown thinning and dieback, epicormic shoots, and bark splits are difficult to identify [12].

The detection of EAB infestation in North America was delayed until 2002, when the species became fully established, propagating across the region with a rate of spread of up to $12.97 \mathrm{~km} /$ year, posing a major ecological and economic threat to trees in urban and forested areas of North America [11]. Although there are few economic impact studies related to forest pest infestations in Canada [13], it has been estimated that the US will suffer economic losses of as much as 10.7 billion dollars to treating and replacing infested street trees [14] and up to an additional 1 billion in private property restoration [15]. Ecological threats to urban forests are extensive, as city ash trees provide a wide range of benefits to the urban environment, including maintaining air quality, prevention of soil erosion, provision of food and shelter for wildlife, and regulation of climate [16]. Rural forests are at risk of altered forest composition posing negative effects on ecosystem function [17]. An improved understanding of EAB behavior and spread may aid in the eradication of the pest and mitigate economic and environmental losses.

EAB outbreak can be conceptualized as a complex system where population dynamics and spatiotemporal patterns of infestation can be difficult to predict. Its complexity stems from non-linearity within the system as a result of changing dynamical relationships between the adaptive beetles and their ash tree hosts, where individual behavior is altered in order to maximize fitness and ensure survival. Non-linearity also stems from environmental feedback, where behavior of the EAB is influenced by elements such as wind, climate, or human interaction. In addition, the insect infestation phenomenon is subject to bifurcation, abrupt and often surprising changes in the structure and function of the system in response to events such as forest fire, flood, climate change, and species collapse. EAB infestation is driven from the bottom up, where these interactions occurring at the local scale generate complex, emergent patterns of insect infestation at the forest stand scale or regional scale causing important environmental, social and economic damage to host landscapes.

Current modeling approaches simulate theoretical EAB behavior on local scales [7], model EAB dispersal in a spatial context using probability exponential decay functions [18] and differential equations [19]. The relationship between EAB infestation and climate has been examined [8,20], as well as the estimate of the economic impacts of the insect infestations [14,21]. Although useful, these studies use approaches that do not address the EAB infestation as a complex system, primarily in a US context.

There is a need for the development of a modeling approach that can help to understand and forecast the spatiotemporal dynamics of $E A B$ spread at regional scale and represent the $E A B$ as a complex system to incorporate important mechanisms of emergence, adaptation, and bifurcation. In addition, it would be useful to address EAB infestation within a Canadian context; however, this would mean modeling in a data scarce environment. Southwestern Ontario in particular, where EAB infestation was initially identified in Canada, lacks geospatial data representing real-world EAB spread 
across the forest landscape over time. This naturally presents a challenge in model creation and in testing how well the model captures EAB propagation. Although there have been a number of efforts to capture large-scale spatial patterns of EAB spread using remotely sensed imagery [22,23], early eradication measures such as the removal of infested trees can distort these findings. Furthermore, lack of tree inventory data in the region makes representation of the forest environment that the EAB propagates an additional challenge. The modeling and analysis of EAB propagation using a bottom-up complex systems approach may have the potential to instead use information from the literature to represent the local dynamics in EAB infestation and generate patterns of spread. Even with a lack of system-level data, modeling the system from the bottom up can further our understanding of the mechanisms that govern the propagation of the infestation to aid in the management of infested regions and the protection of regions in Canada not yet impacted.

Cellular automata (CA) approach is mathematical conceptualization of a complex system that employs a bottom-up modeling methodology and is capable of integrating geographic information systems (GIS) and geospatial data to represent emerging patterns of spatiotemporal phenomena. By representing the local dynamics between pest and host from which large-scale patterns emerge, mechanisms such as adaptation and bifurcation that drive the complex behavior of the system can be represented. In addition, it has been reported in the literature that a bottom-up approach is capable of representing phenomenon with a lack of observational data, since information is more accessible in terms of building the local dynamics that make up a system that will build a model of an entire population [1].

Therefore, the main objective of this study is to explore the use of cellular automata to develop a geosimulation modeling framework capable of capturing complex emergent spatiotemporal behavior of EAB spread at the regional scale with the challenge of data scarcity. GIS, multi-criteria evaluation techniques (MCE), and CA were used in this study to simulate EAB spread in response to ash tree susceptibility. The study used geospatial datasets to create hypothetical landscapes for Windsor, Ontario, Canada in the year 2002, where the first EAB infestation was initially identified. Various landscape types, namely the urban landscape, the rural-urban landscape, and the rural landscape were created for the purpose of representing different realistic settings where the EAB occur. Each of these landscape types are composed of varying distributions and biologically heterogeneous ash tree hosts. The developed geosimulation model incorporated aspects of environmental variation including wind and temperature to determine the influence of these factors across each landscape.

Pending availability, the implementation of the proposed EAB CA-model framework on real geospatial data can provide a powerful decision-making tool for aiding in developing strategy to minimize potentially damaging and expensive pest control activities while effectively mitigating insect species spread.

\section{Complex Systems Theory for Modeling Insect Infestation}

Complex systems theory uses a bottom-up approach to analyze the behavior of a system, more specifically, to understand how local interactions between system elements with non-linear collective behavior generate patterns at a larger scale. Ecological systems, including insect infestation, are identified to behave as complex systems as they are composed of a network of heterogeneous individuals, dynamic local interactions and varying resource bases [24-26]. Variations within the system are often amplified by non-linear processes [27], adaptation, and both individual and environmental change, fostering emergent and unpredictable behavior.

Cellular automata (CA) are a common complex systems modeling approach that can capture both the spatial and temporal dynamics inherent to dynamic geographic phenomena [28]. CA, discrete in space and time, is composed of a grid of cells that can represent geographic space when linked to a raster-based GIS framework. The state of each cell changes over time as a function of simple transition rules and the states of all cells in the surrounding neighborhood [29]. The characteristics of 
CA make the method suitable for representing complex spatiotemporal phenomena. The CA can be expressed as:

$$
S_{x y}^{T_{i+1}}=f\left(S_{x y}^{T i}, N_{x y}^{T i}\right)
$$

where $S_{x y}^{T_{i}}$ and $S_{x y}^{T_{i+1}}$ are the states of a cell at a location $(\mathrm{x}, \mathrm{y})$ at time Ti and Ti+1, $N_{x y}^{T i}$ represents the neighborhood surrounding the cell at time Ti at location $(x, y)$, and $f$ represents the function of transition rules that determine how the state of a cell will change in the next Ti+1 step.

Complex systems modeling approaches based on CA have been used for simulating ecological phenomena [30-34]. The use of CA to model insect populations in forest communities has also been explored in data scarce situations $[35,36]$. At a regional scale, CA modeling has been found to be an appropriate approach for simulating spatial patterns of tree death resulting from insect infestation within a changing forested land-cover and with insufficient amount of tree infestation data $[35,37]$ and mountain pine beetle propagation [38].

Given that CA allows for the representation of complex dynamics between the EAB pest and its ash tree host providing the potential to reveal emergent behavior as a result of interacting with various landscape types, it is useful to use CA methodology as an appropriate choice for the representation and analysis of the spatiotemporal dynamics of EAB infestation when there is a lack of data available. Using GIS, MCE and the CA approach, namely its cellular structure and discrete cell states, this study aims to explore the use of a complex approach to represent the complex dynamics between the emerald ash borer pest and its ash tree host, and enables the representation of patterns of EAB infestation over space and time.

\section{Methods}

\subsection{Study Site and Datasets}

The developed CA-EAB geosimulation model of EAB insect infestation has been applied to a hypothetical case study of the EAB infestation in the Essex County in Windsor, Ontario, Canada $\left(42^{\circ} 17^{\prime} \mathrm{N} ; 83^{\circ} 00^{\prime} \mathrm{W}\right)$ (Figure 1) where the first infestation was first identified in Canada. The EAB infestation was simulated to cover the period from May 2002 to August 2003. The datasets used for this study are described as follows:

(1) GIS data layer providing an initial location of EAB infestation in the City of Windsor in 2002. Additional data from the literature provides information on the average rate of spread where the first North American outbreak of EAB in Michigan. The US had a rate of spread of $12-13 \mathrm{~km} /$ year during this time through natural and long distance dispersal [11].

(2) GIS raster files of $10 \mathrm{~m}$ spatial resolution were generated to represent three different hypothetical landscape types for forest in urban, rural-urban fringe, and rural settings in and surrounding the City of Windsor. The raster data layers were created using vector land use data acquired from Land Information Ontario (LIO) [39]. The acquired LIO land use data have determined the actual distribution of trees in each of the three landscape types; however, due to the unavailability of tree inventory data for this region, the exact location of individual ash trees is unknown. In addition, the biological characteristics of the ash trees such as age and size were derived from the literature to generate the realistic biological characteristics of ash trees within three landscape types.

(3) Weather and meteorological data for twelve stations distributed by the Government of Canada [40]. This data includes average wind direction and monthly temperature data for a period of two years. 

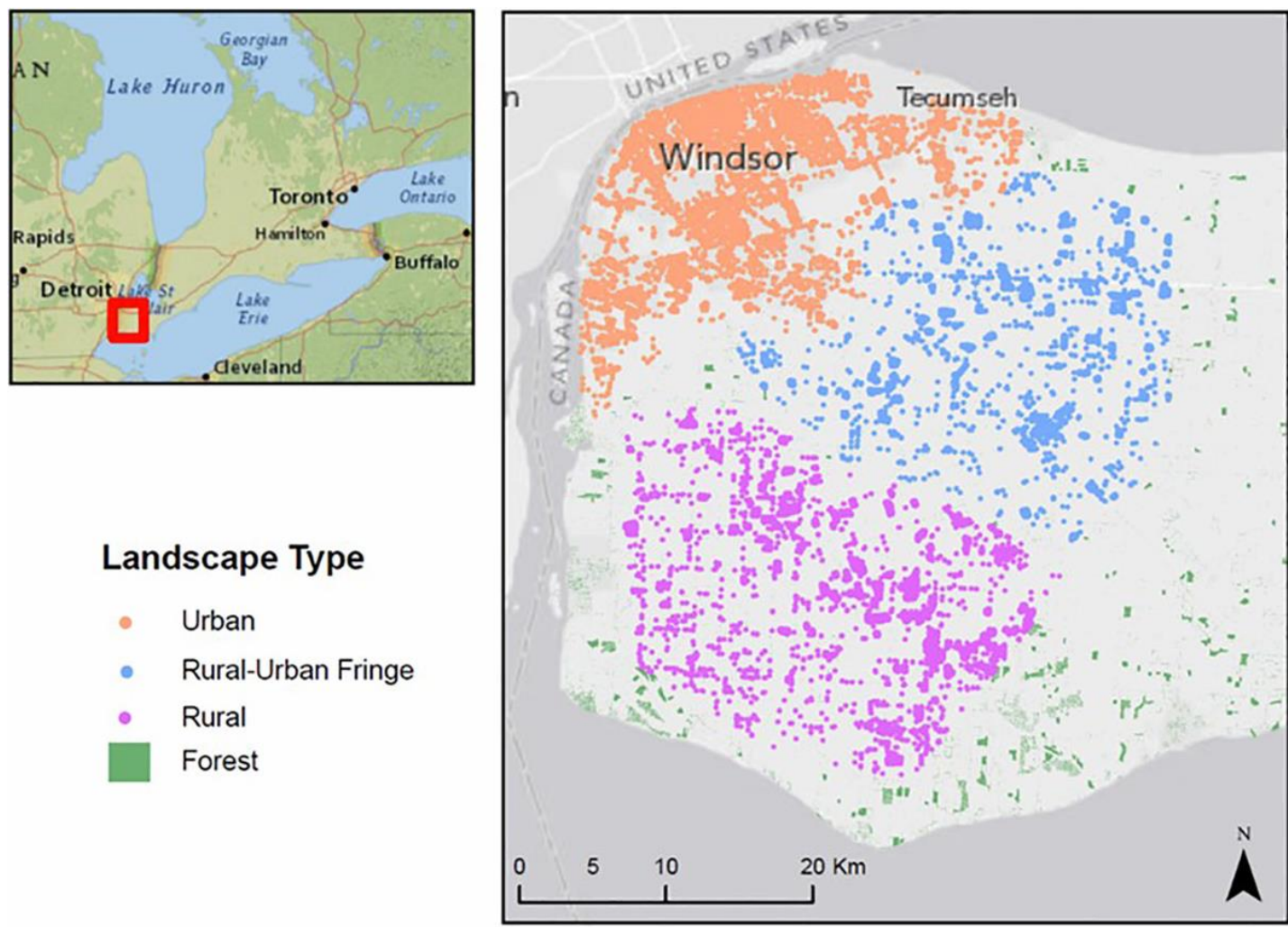

Figure 1. Study site, Windsor, Canada, depicting different spatial patterns of the ash trees characterizing three landscapes: urban, rural-urban fringe and rural.

\begin{tabular}{|c|c|c|c|c|c|c|c|c|c|c|c|}
\hline Jan & Feb & Mar & Apr & May & Jun & Jul & Aug & Sept & Oct & Nov & Dec \\
\hline \multicolumn{2}{|c|}{ Inactive Larvae } & \multicolumn{2}{|c|}{ Pupae } & & & & & & \multicolumn{3}{|c|}{ Inactive Larvae } \\
\hline & & & & \multicolumn{8}{|c|}{ Active Larvae } \\
\hline
\end{tabular}

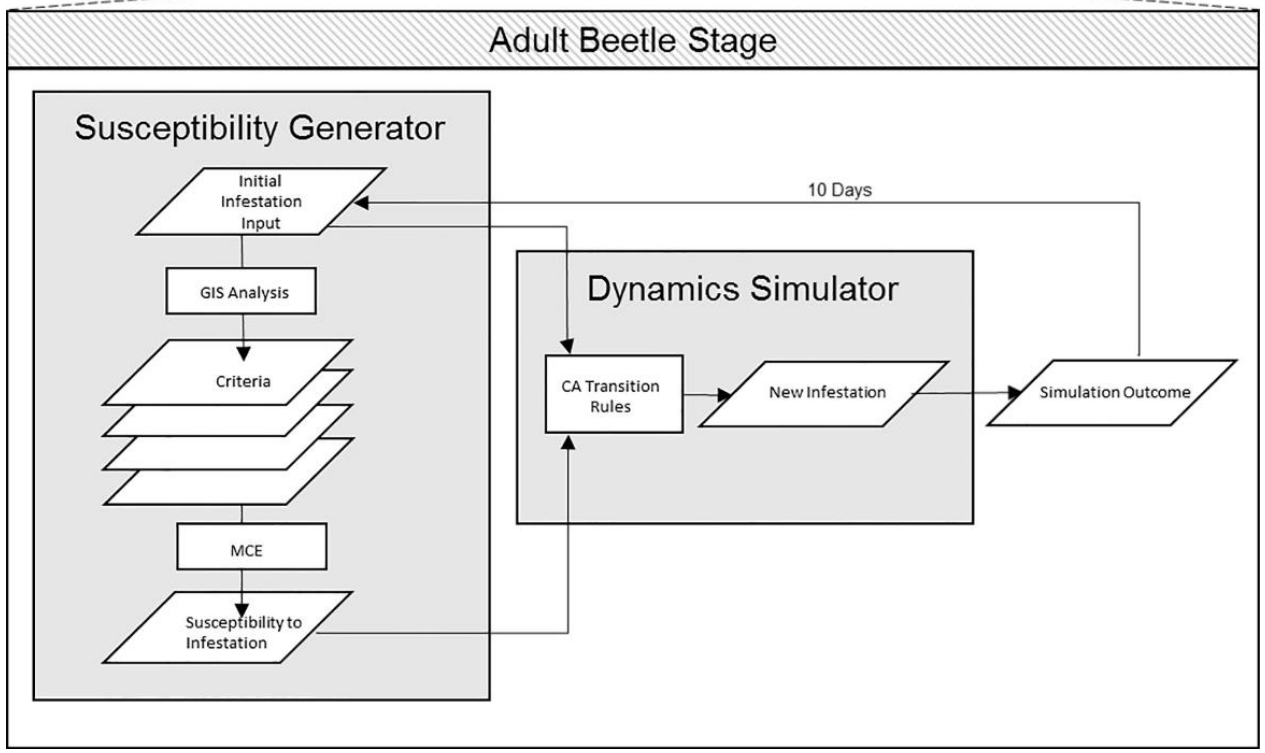

Figure 2. The structure of $C A-E A B$ model that generates $E A B$ propagation during the adult beetle stage in the EAB lifecycle and that consists of two sub-models, a susceptibility generator and a dynamics simulator. 


\subsection{Model Structure}

The CA-EAB model is composed of two sub-model components, including (1) an ash tree susceptibility generator and (2) an insect infestation dynamics simulator (Figure 2). A multi-criteria evaluation approach was integrated to generate the degree of susceptibility of ash to infestation. The proposed model integrates a raster-based GIS and a CA approach to simulate the dynamics between pest and ash tree host, which occur during the adult beetle stage, the only stage where the EABs are active during the EAB lifecycle. The three landscape scenarios are used to aid in further understanding of the underlying mechanisms of forest composition and density that govern EAB spread including ash tree distribution, wind, and temperature. The details on model components are presented in the following sections.

\subsubsection{Model Component 1: Tree Susceptibility}

Each tree has a varying degree of susceptibility to EAB infestation as a function of the tree's spatial and biological characteristics including (1) tree type; (2) distance from infested ash; (3) distance from roads; (4) distance from highways; (5) density of ash in the stand; (6) age of ash; (7) size of ash, (8) wind direction; and (9) air temperature. Model Component I uses a GIS based multi-criteria evaluation (MCE) method to quantify the ash tree's overall susceptibility to EAB infestation based on the above criteria. Susceptibility functions $(F n)$ are developed to generate susceptibility values for each criterion individually, determining how susceptible a tree is on a scale from 0 (not susceptible) to 1 (most susceptible). Each susceptibility function (F1, F2, . . Fn) is weighted based on the significance of their role in influencing the susceptibility of an ash tree to EAB infestation in comparison to other criteria. Susceptibility values from all criteria are combined to obtain the overall susceptibility. The MCE is expressed as follows:

$$
y=\operatorname{MCE}(F 1, F 2, F 3 \ldots F n)
$$

where an ash tree's overall susceptibility $y$ is a function of the weighted combination of the susceptibility values for each criterion $(F 1, F 2, F 3, \ldots, F n)$.

The first criterion $(F 1)$ is tree type. Ash trees are the only tree type susceptible to EAB infestation. This can be expressed as a binary membership where cells not containing living ash trees are assigned a value of 0 and cells containing living ash are assigned a value of 1 . Although evidence suggests some types of North American ash trees may be more susceptible than others, the proposed model operates under the assumption that the ash tree type does not impact the level of susceptibility.

The remaining criteria ( $F 2$ - F9) are represented using susceptibility functions (Figure 3a), where an ash's membership to the "susceptible" or "not susceptible" class is determined along a membership to a gradual scale rather than a binary one. Susceptibility functions were developed based on knowledge collected from the literature on EAB behavior (Figure 3). Sensitivity analysis was performed to verify the choice of linear functions. The use of positive or negative exponential functions either overestimated or underestimated the simulated rate of infestation. For example, a negative exponential function in place of the negative linear function in the distance from infested trees for the urban landscape resulted in a rate of spread that does not match the rate of spread observed in reality. This is a result of higher susceptibility values being assigned to ash trees, which are close in distance to existing infestation. As distance increases, even slightly, susceptibility of ash trees decreases exponentially. The resulting effect is a decrease in rate of spread, simulated by the model.

Distance from infested ash (F2) criterion is chosen, as the proximity of ash to other infested ash trees is a major factor contributing to ash tree susceptibility [7]. Within their lifetime, migrating EAB adults have the ability to travel, on average, $1.4 \mathrm{~km}$ from their place of emergence, indicating that the probability of infestation will decrease as the distance from infested trees increases. At a distance of $1.4 \mathrm{~km}$ from infested trees, susceptibility decreases to 0 . As such, this relationship can be represented by an inverse linear membership function where trees are more susceptible to infestation the closer they are to trees that are already infested (Figure 3a, (1)). 
In addition to short distance dispersal, it is becoming increasingly evident that long distance dispersal plays a prominent role in spatial patterns of EAB infestation [41]. Therefore, the distance from roads (F3) and highways (F4) has been chosen as criteria. The correlation between roads and highways, and establishment of new outlier populations of $\mathrm{EAB}$, and infested regions that develop ahead of the primary infestation front have been identified [41]. These outlier populations typically grow, coalesce, and ultimately increase the speed of infestation [42]. This correlation between transportation networks and outlier populations can be attributed to human transportation of infested ash materials such as nursery stock, saw timber, and wood packaging material. In addition, firewood moves through informal pathways over long distances making infested firewood nearly impossible to identify, track, and regulate [43]. Recent research reveals that outlier populations may also be attributed to "insect hitchhiking" via attachment to automobiles [41,43,44]. Roads and highways represent human influence on EAB dispersal in which ash trees in close proximity to roads or highways are the most susceptible. This relationship can be represented by an inverse linear membership function where trees are more susceptible to infestation the closer they are to transportation networks (Figure 3a, $(2,3)$ ).

1)

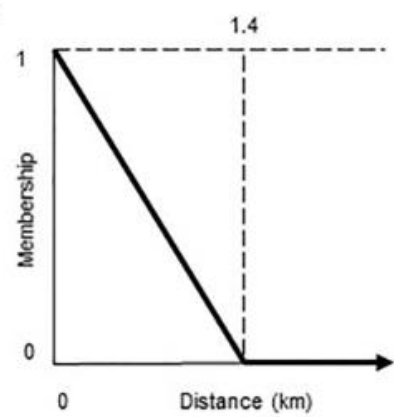

4)

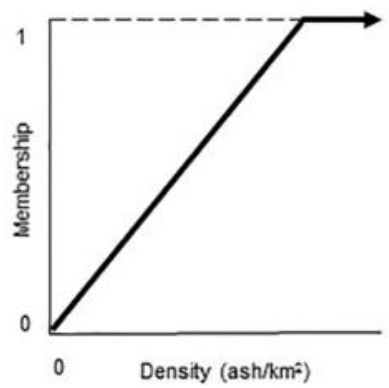

2)

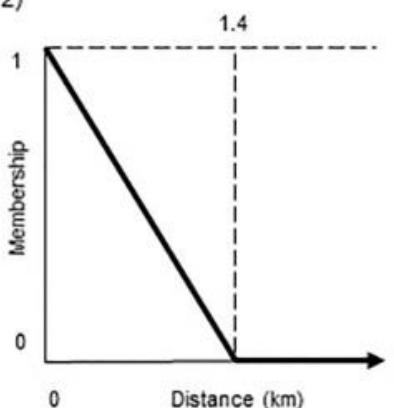

5)

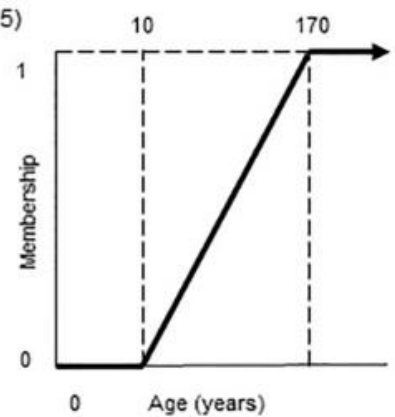

3)

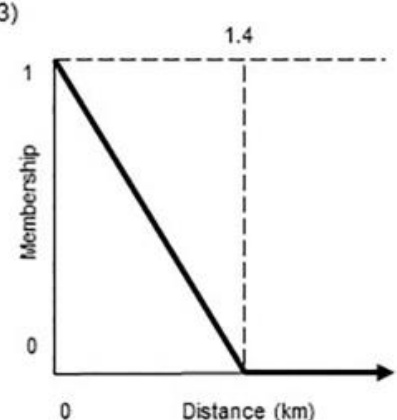

6)

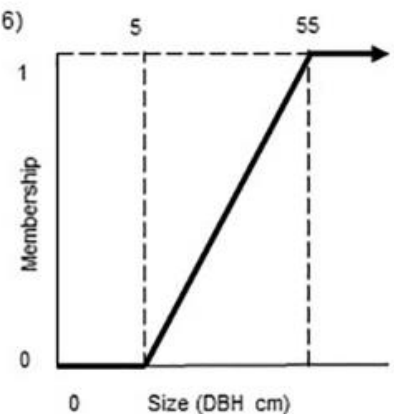

7)

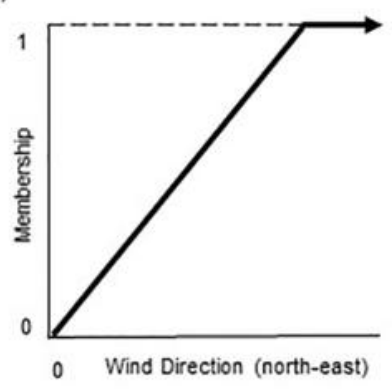

8)

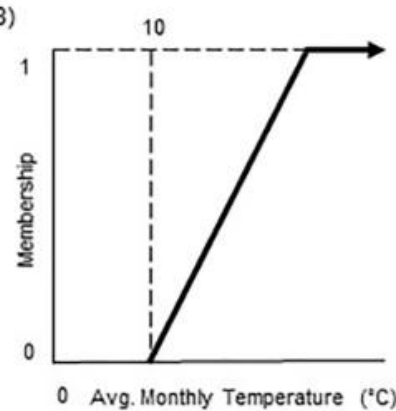

(a)

Figure 3. Cont. 


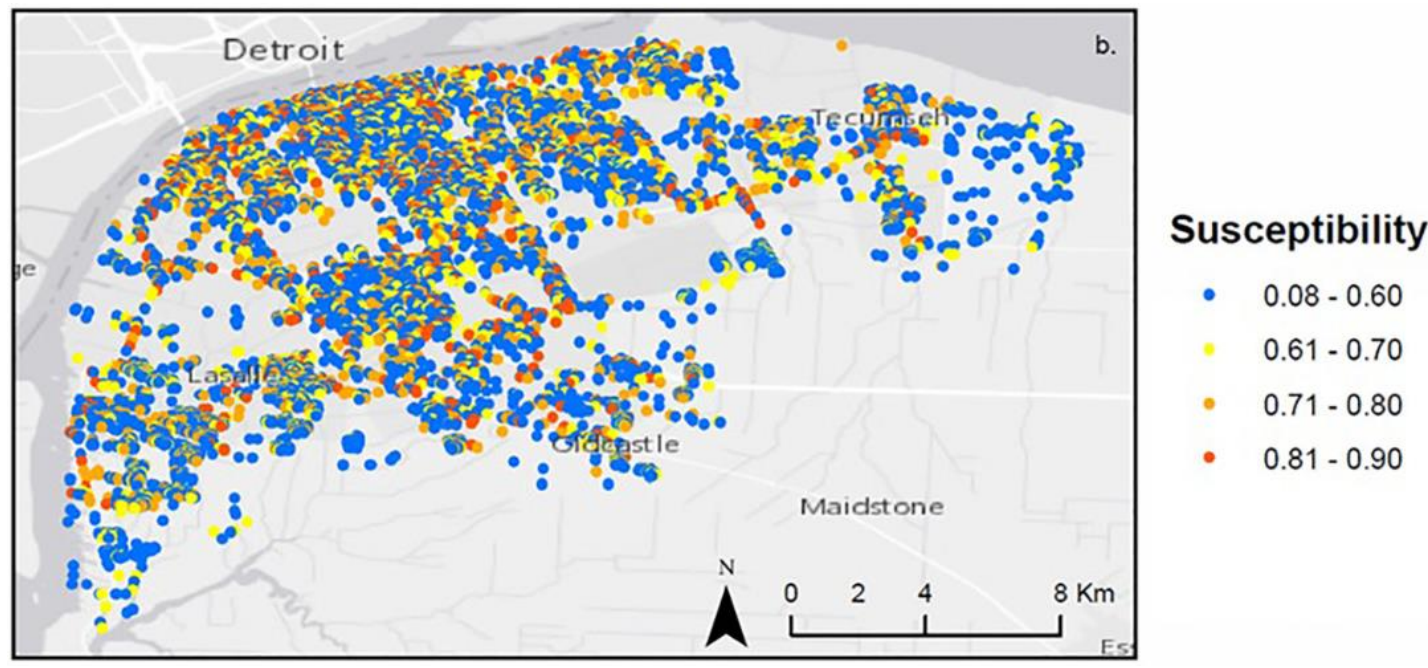

(b)

Figure 3. Susceptibility functions for each ash tree representing (a) (1) distance from infested trees; (2) distance from roads; (3) distance from highways; (4) ash tree density in the stand; (5) ash tree age; (6) ash tree size; (7) wind; and (8) air temperature, combined in (b) to produce overall susceptibility.

Adult beetles rely on the source of ash tree leaves for food, and, as a result, EAB females prefer to lay their eggs in areas with a higher proportion of ash trees in the stand [42]. This indicates that the probability of infestation will increase as stand density increases. Therefore, the density of ash trees (F5) has been chosen as one of the criteria. The exact density threshold has not been identified within the literature. However, the use of a susceptibility function allows for the representation of density of ash as an influence in determining ash tree susceptibility without needing quantitative threshold values. The function simply scales the variation of ash tree densities, where higher densities have susceptibility closer to 1 . This relationship can be represented by a linear membership function where stands with a higher density of ash are more susceptible (Figure 3a, (4)).

The next criteria are related to the tree age (F6) and tree size (F7). EAB are constrained by tree size and age in that ash that have a DBH of less than $5 \mathrm{~cm}$ or are younger than 10 years of age are highly unsusceptible to infestation as the interior cambium cannot provide enough phloem to sustain larvae [7]. Susceptibility to infestation based on tree age is represented by a linear membership function where trees are not susceptible (susceptibility membership of 0 ) if they are less than 10 years old. Susceptibility increases as ash tree age increases until the age of 170 years, representing the maximum age of ash tree species. Ash trees that are 170 years old are of the highest susceptibility and thus have a membership value of 1 (Figure 3a, (5)). Susceptibility to infestation based on tree size is represented by a linear membership function where trees are not susceptible if they are less than $5 \mathrm{~cm}$ DBH. Susceptibility increases until $55 \mathrm{~cm} \mathrm{DBH}$, at which time it reaches the maximum value of susceptibility (Figure 3a, (6)).

During the month of June, when the adult beetles fly to find food and reproduce, the primary wind direction in the Essex region is to the northeast. Although capable of flight upwind, insect species that respond to pheromones, such as at the $\mathrm{EAB}$, will typically fly downwind until pheromones are encountered [45]. The wind (F8) criterion is thus selected. Similar to the density of ash and temperature criteria, the use of susceptibility functions does not require a threshold value. As such, susceptibility to infestation based on wind can be represented by a linear membership function where trees that are northeast of infested trees are most susceptible (Figure 3a, (7)).

Similarly, temperature is selected as a criterion given that microclimatic factors such as light, temperature, wind, and turbulence all influence insect dispersal [46]. EAB development and emergence as an adult beetle is highly dependent on weather conditions. In particular, egg hatch and flight is 
limited to occur during warm and sunny weather conditions. The use of susceptibility functions to represent the influence of temperature on EAB infestation does not require threshold values. Therefore, susceptibility to infestation based on temperature $(F 9)$ is represented by a linear membership function where trees are most susceptible in warmer temperatures (Figure 3a, (8)).

According to a study that explored which abiotic and biotic factors have the most to least impact on $\mathrm{EAB}$ habitat selection, both logistic regression and Maxent modeling identified the distance to known locations of the $\mathrm{EAB}$ as considerably more important than any other variable influencing the spread of the EAB [47]. This was incorporated in the susceptibility generator by assigning the highest weighting to the distance from infestation criteria. Additional factors, such as highways more frequently travelled by vehicles carrying infested commercial products, are assigned higher weights in the MCE calculations than roads, as there is evidence that, along highways, a faster rate of spread and a higher susceptibility to infestation can be identified [43,48]. The weighted criteria are combined in the order of significance according to the literature: distance from infestation, wind and temperature, age and size, highway, roads, and density. The weights were determined using the analytic hierarchical process (AHP) method [49] and are detailed in Table 1. The MCE generates output $y$, a geographic representation of the total susceptibility of ash to $E A B$ infestation on a scale from 0 to 1 as a function of all the criteria. The map of calculated levels of overall susceptibility of ash trees to EAB infestation is presented in Figure 3b.

Table 1. The weights of the susceptibility factors that are used in the MCE component of the model without the influence of wind or temperature (a); including wind or temperature (b), and including both wind and temperature (c).

\begin{tabular}{|c|c|c|c|}
\hline Category & & Priority & Rank \\
\hline 1 & Distance & 54.2 & 1 \\
\hline 2 & Age and Size & 23.9 & 2 \\
\hline 3 & Highways & 13.9 & 3 \\
\hline 4 & Roads & 6.2 & 4 \\
\hline \multirow[t]{2}{*}{5} & Density & 3.7 & 5 \\
\hline & Consistency & $7.80 \%$ & \\
\hline \multicolumn{4}{|c|}{ (a) } \\
\hline Category & & Priority & Rank \\
\hline 1 & Distance & 40.9 & 1 \\
\hline 2 & Wind or Temperature & 32.3 & 2 \\
\hline 3 & Age and Size & 13.9 & 3 \\
\hline 4 & Highways & 6.4 & 4 \\
\hline 5 & Roads & 3.8 & 5 \\
\hline \multirow[t]{2}{*}{6} & Density & 2.6 & 6 \\
\hline & Consistency & $7.10 \%$ & \\
\hline \multicolumn{4}{|c|}{ (b) } \\
\hline Category & & Priority & Rank \\
\hline 1 & Distance & 37.6 & 1 \\
\hline 2 & Wind & 22.1 & 2 \\
\hline 3 & Temperature & 22.1 & 3 \\
\hline 4 & Age and Size & 8.1 & 4 \\
\hline 5 & Highways & 4.7 & 5 \\
\hline 6 & Roads & 3.2 & 6 \\
\hline \multirow[t]{2}{*}{7} & Density & 2.1 & 7 \\
\hline & Consistency & $6.00 \%$ & \\
\hline
\end{tabular}




\subsubsection{Model Component II: Spatial Dynamics Simulator}

The second component of the EAB infestation model simulates the dynamics of EAB spread in response to the susceptibility values generated for ash trees in Model Component I within the various landscapes. The model is calibrated using real world rates of spread identified within the literature to obtain a rate of spread of $12-13 \mathrm{~km}$ /year through natural dispersal, the average recorded rate of spread (see Section 3.4). The CA in Component II is based on the function of transition rules as follows: If there are non-infested ash trees within the neighborhood of an infested ash tree, then ash trees which are of the highest susceptibility to infestation will become infested. High susceptibility is defined as having a value greater than 0.6. Trees with a susceptibility of less than 0.6 will not become infested. Trees that are already infested stay infested and will eventually die.

The epicenter of the EAB infestation in Windsor, Ontario was acquired from the geospatial datasets obtained by the CFIA and was used to initialize the simulation. In the real world, EAB disperse each year from late May to early August, when EAB adults take flight to lay their eggs in the most susceptible trees. The CA-EAB model simulates the infestation for a total of 24 iterations $\left(T_{i+24}\right)$, where each iteration is equivalent to a temporal resolution of 10 days, which cover the overall period of two years. With each iteration, from May $2002\left(T_{i+1}\right)$ to August $2003\left(T_{i+24}\right)$, the model simulates a new infestation of ash trees, changing the susceptibility of non-infested trees as a function of their proximity to other infested ash trees, age, and size.

\subsection{Scenarios}

\subsubsection{Landscape Scenarios}

In order to realistically represent the landscapes in which the EAB infestation propagates and investigate the differences in the dynamics of propagation, three unique landscape scenarios were developed (Figure 1). These landscapes are based on the different spatial arrangements and biological characteristics of the ash tree host found across Southwestern Ontario using geospatial data and the literature. They are described as follows:

Urban Landscape Scenario is represented by the City of Windsor. Windsor is predominantly composed of residential, commercial, industrial, and some recreational space, located in the west end of the city. Popular along city streets, on private property landscapes, and throughout urban parks and open spaces, ash trees are the principal tree species of urban Southwestern Ontario [16]. Urban ash trees are typically 10 years of age or older when they are planted, deeming the majority of urban ash 10 years or older with a DBH of $5 \mathrm{~cm}$ or more.

Rural-Urban Fringe Scenario is located at the boundary that lies between the City of Windsor, Ontario and agricultural land along its borders. This region is composed of a mosaic of the urban landscape including residential and commercial regions, crops, pastures, large tracts of abandoned farmland, fallow lands and forested regions. Forested regions are typically composed of a minimum of $7 \%$ of ash tree species, which are randomly and widely dispersed across the landscape and loosely connected through the small corridors of trees along roadways, between agricultural plots, and along waterways.

Rural Landscape Scenario consists mainly of patches of forested areas and agricultural land, including crop and pasture land. Forested regions are connected by corridors of trees along agricultural fields, roads, and waterways. Rural ash trees live on average up to 170 years with a maximum DBH of $55 \mathrm{~cm}$.

\subsubsection{Climate Scenarios}

Wind Scenario is developed in order to represent the spatiotemporal factors that influence EAB infestation, a wind scenario was developed. The dominant wind direction during all summer months from May to August is northeast (Ontario Weather Network, 2015). An additional CA sub-model 
simulates the effect of wind on EAB propagation where all ash tree located northeast of an infested ash tree is of increased susceptibility.

In order to better represent the microclimatic impacts that influence EAB infestation in the real world, Climate Scenarios for the years 2002 and 2003 were developed to represent the influence of surface temperature and wind on adult EAB movement at the regional scale. Adult EAB are only active during the summer months from May through to August. As such, two temperature scenarios have been considered using monthly temperature data from 2002 with an average temperature of $22{ }^{\circ} \mathrm{C}$ and from 2003 with an average temperature of $26^{\circ} \mathrm{C}$. Weather and meteorological data were used from twelve Ontario weather stations in the region with GIS interpolation using inverse distance weighting (IDW) to represent surface temperature continuously across each landscape scenario at a $10 \mathrm{~m}$ spatial resolution.

Wind and temperature were combined in all three landscape scenarios with the goal of generating simulation outcomes that produce more realistic patterns of spread in the combined Landscape, Climate $\mathcal{E}$ Wind scenarios. Spatial patterns of EAB are influenced by monthly temporal changes in temperature and wind, rather than simply reacting to the spatially derived characteristics of the ash tree. Wind and temperature were added into the MCE and weighted just less than distance from infestation.

\subsection{Model Calibration}

The calibration process uses rates of spread identified within the literature. In the first North American outbreak of EAB in Michigan, the US had a rate of spread of 12-13 km/year through natural dispersal [11]. Distances of 20+ km, up to a maximum recorded distance of $42 \mathrm{~km}$, have been observed in some regions. These long distances of EAB spread can only be explained through the mechanism of human assisted movement through the transport of ash infested products or the hitchhiking of EAB on vehicles $[18,41]$. These rates of spread match the baseline rates of spread for each landscape, without any influence of wind and temperature. The average rate of spread between all landscapes simulated for 2002 was $9.9 \mathrm{~km}$ with a maximum distance of $31 \mathrm{~km}$. The average rate of spread between all landscapes simulated for 2003 was $10.5 \mathrm{~km}$ /year with a maximum distance of $32 \mathrm{~km}$. The rate of spread obtained with model outputs is close to real-world rates of infestation for the region.

The following parameters that were adjusted during this process are the most suitable use of neighborhood sizes for each landscape scenario and the appropriate value of susceptibility whereby a tree may transition from uninfested to infested. Each landscape tested the use of different sizes of neighborhoods to apply transition rules. It was found that the Urban Landscape, Rural-Urban Fringe, Rural Landscape Scenarios using extended Moore neighborhoods with the dimensions $1.5 \mathrm{~km} \times 1.5 \mathrm{~km}$, $2 \mathrm{~km} \times 2 \mathrm{~km}$ and $1.7 \mathrm{~km} \times 1.7 \mathrm{~km}$, respectively, generated the most realistic results. Neighborhoods of smaller size did not capture a continuous propagation of the infestation, rather the infestation propagation stopped altogether. In addition, susceptibility values were tested to find the appropriate cut off value for trees that would not be of the appropriate susceptibility for infestation. A susceptibility value of +0.6 was chosen where only ash trees with this value or higher have the potential to become infested. The value of 0.6 ensures that $\mathrm{EAB}$ infestation patterns are simulated close to reality.

\section{Results}

The CA-EAB infestation model was implemented using ESRI's ArcGIS [50] and IDRISI [51] software. Simulation results were generated for a two-year period for the years 2002 and 2003 for each of the landscape scenarios. Climate and wind scenarios were applied to each of the landscape scenarios independently as well as a combination.

\subsection{Landscape Scenarios}

Simulation results for generated patterns of EAB infestation from May through August 2002 and 2003 are presented in Figures 4-6 for the Urban Landscape Scenario, the Rural-Urban Fringe Scenario, and 
the Rural Landscape Scenario, respectively. The percentages of the overall infested trees over time are presented in Figure 7 for all three landscape scenarios.
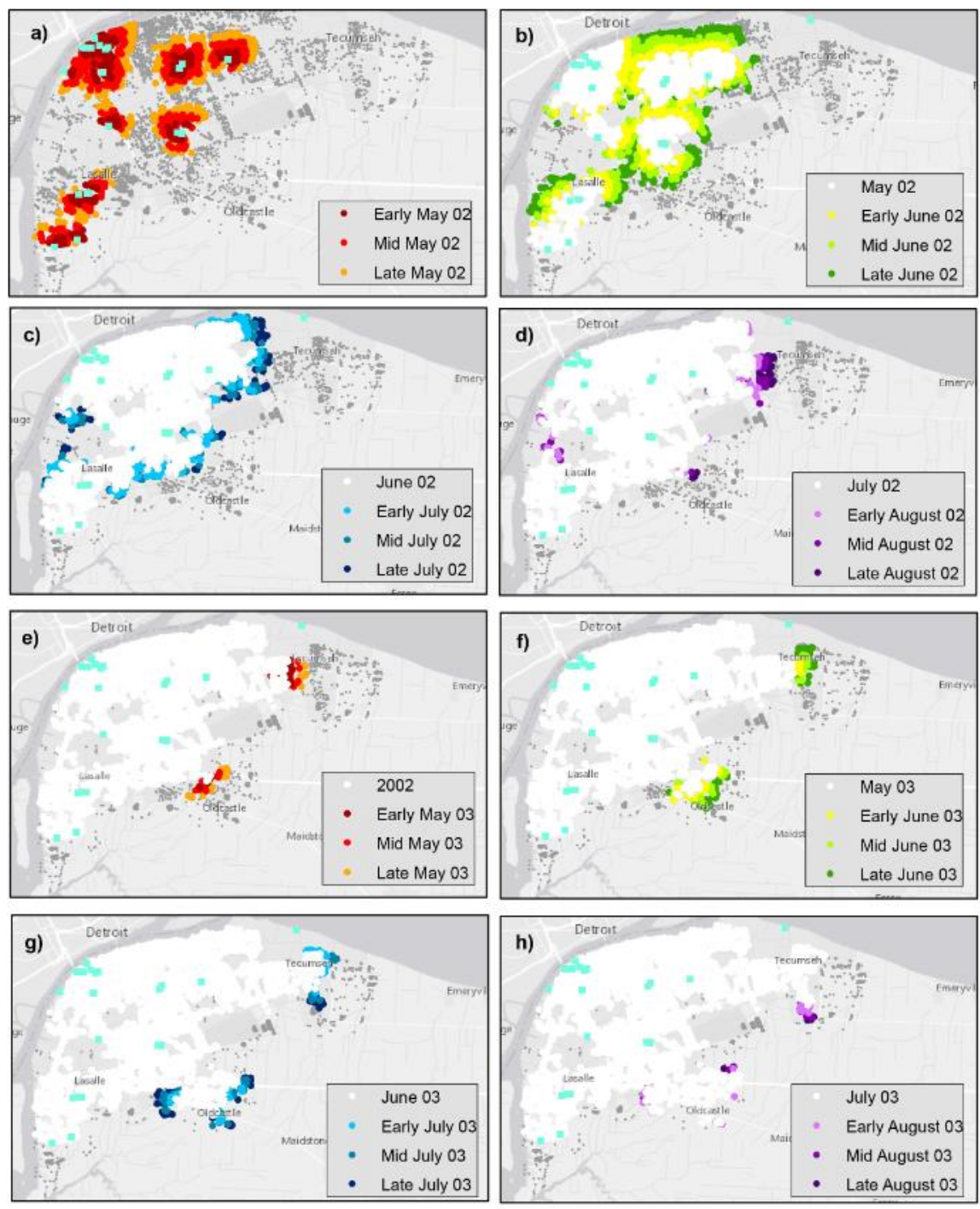

Initial Infestation

Non-Infested Ash

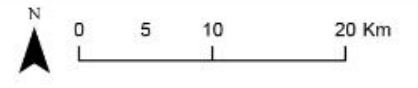

Figure 4. Simulation results of EAB infestation spatial patterns generated for (a) May 2002; (b) June 2002; (c) July 2002; (d) August 2002; (e) May 2003; (f) June 2003; (g) July 2003, and (h) August 2003 for the Urban Landscape Scenario.

The obtained simulation results for the Urban Landscape Scenario (Figure 4) indicate that the rate of spread was high until late July 2002, when the majority of susceptible ash trees became infested. In 2003, the EAB rate of spread slowed; however, new ash trees continued to become infested until the end of the simulation. In total, $48 \%$ of ash trees became infested after two years (Figure 7a).

Spread of infestation obtained for the Rural-Urban Fringe Scenario (Figure 5) began with a gradual linear increase until early July 2002, when infestation tapered off, and little to no new ash became infested for the rest of the time until the end of the simulation in August 2003. In the Rural-Urban Fringe Scenario, $10 \%$ of healthy ash trees became infested after two years (Figure $7 \mathrm{~b}$ ).

The simulated patterns for Rural Landscape Scenario (Figure 6) depict that EAB infestation differs from the other two landscape scenarios. The rate of spread increased rapidly as forested regions composed of high densities of ash trees became infested. Rates of infestation slowed as EAB infested 
ash of lower density where forested regions were separated, and then increased again once the EAB infests another forested region. 34\% of healthy ash trees were becoming infested after two years (Figure 7c) for the Rural Landscape Scenario.

The obtained results indicate that the Urban Landscape Scenario was the most prone to infestation, exhibiting the fastest rate of spread and the highest percentage of infestation. The Rural-Urban Fringe Scenario demonstrated the least susceptibility to EAB infestation, demonstrating the slowest rate of spread and the lowest percentage of infestation. The rate of spread and percentage of ash infested for Rural Landscape Scenario fell between the two.

\subsection{Climate Scenarios}

The simulation outputs changed in response to temperature and wind scenarios implemented into the landscape. Spatial patterns of spread were generated for May $2002\left(T_{i+3}\right)$ and June $2002\left(T_{i+6}\right)$ and for simplicity were presented for Urban Landscape Scenario only (Figure 8), where the simulation results obtained for the Urban Landscape with no climatic effects are presented in Figure 8a, temperature effects on the landscape are presented in Figure $8 b$, wind effects on the landscape are presented in Figure $8 \mathrm{c}$, and a combination of wind $\mathcal{E}$ climate effects in Figure $8 \mathrm{~d}$. Since the rate of spread is most pronounced during May and June, comparison is most useful during these two months to see variation in patterns. In addition, the rate of spread in each landscape with the influence of climate are presented in the graph in Figure 7.

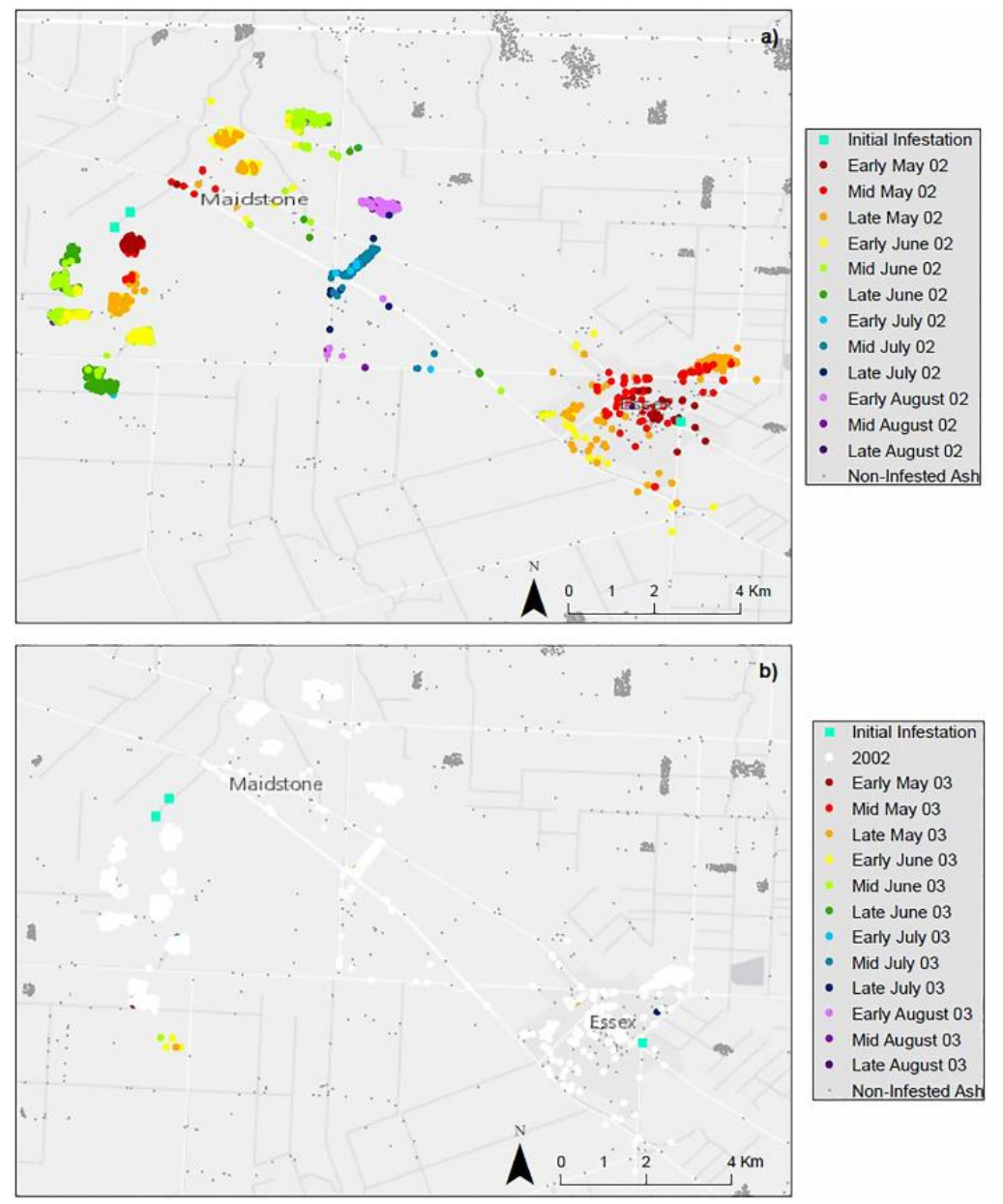

Figure 5. Simulation results of EAB infestation generated for the years (a) 2002 and (b) 2003 for the Rural-Urban Fringe Landscape Scenario. 
Temperature-The effects of temperature on patterns of EAB spread has been incorporated into the model and the results are presented in Figures $8 \mathrm{~b}$ and 7 . Based on real world climatic datasets, the study site experienced warmer temperatures in the summer of 2003 than in 2002, and, as such, obtained rates of insect spread in the model were higher in 2003. In the model, temperature constrains spread in colder months and accelerates spread in warmer months. The spatial pattern this produces is visible (Figure 8b) in comparison to simulation results that do not take temperature into account (Figure 8a). The rate of spread in each landscape decreased in May 2003, reflecting the cooler temperatures characteristic to these specific months, which in turn decreased the susceptibility of ash trees in the region and resulted in a decreased rate of infestation (Figure 7).

Consistent with all scenarios, even with the influence of temperature, the Urban Landscape Scenario demonstrated the fastest rate of spread and the highest percentage of infestation. The Urban Landscape Scenario simulated infestation of a total of $70.5 \%$ of all ash in the landscape using temperatures from 2002 to 2003 (Figure 7a). The simulation results for the Urban-Rural Fringe Scenario indicate the lowest rate of propagation and the lowest percentage of infestation with a total of $3.3 \%$ of all ash becoming infested by 2003 (Figure 7b). Lastly, the Rural Landscape Scenario has a total of $40.7 \%$ of all ash in the landscape becoming infested in response to 2003 temperatures (Figure 7c).

Wind-The simulation results indicate that wind accelerates spread in some landscape scenarios and constrains spread in others. For example, in the Urban Landscape Scenario, wind accelerated EAB spread, facilitating the spread of EAB infestation further in distance northeast, the direction downwind from initial infestation (Figure 8c). As a result, a total of $65 \%$ of all ash became infested over a period of two years in the Urban Landscape Scenario (Figure 7a), 20\% more than the baseline simulation without effects of climate.

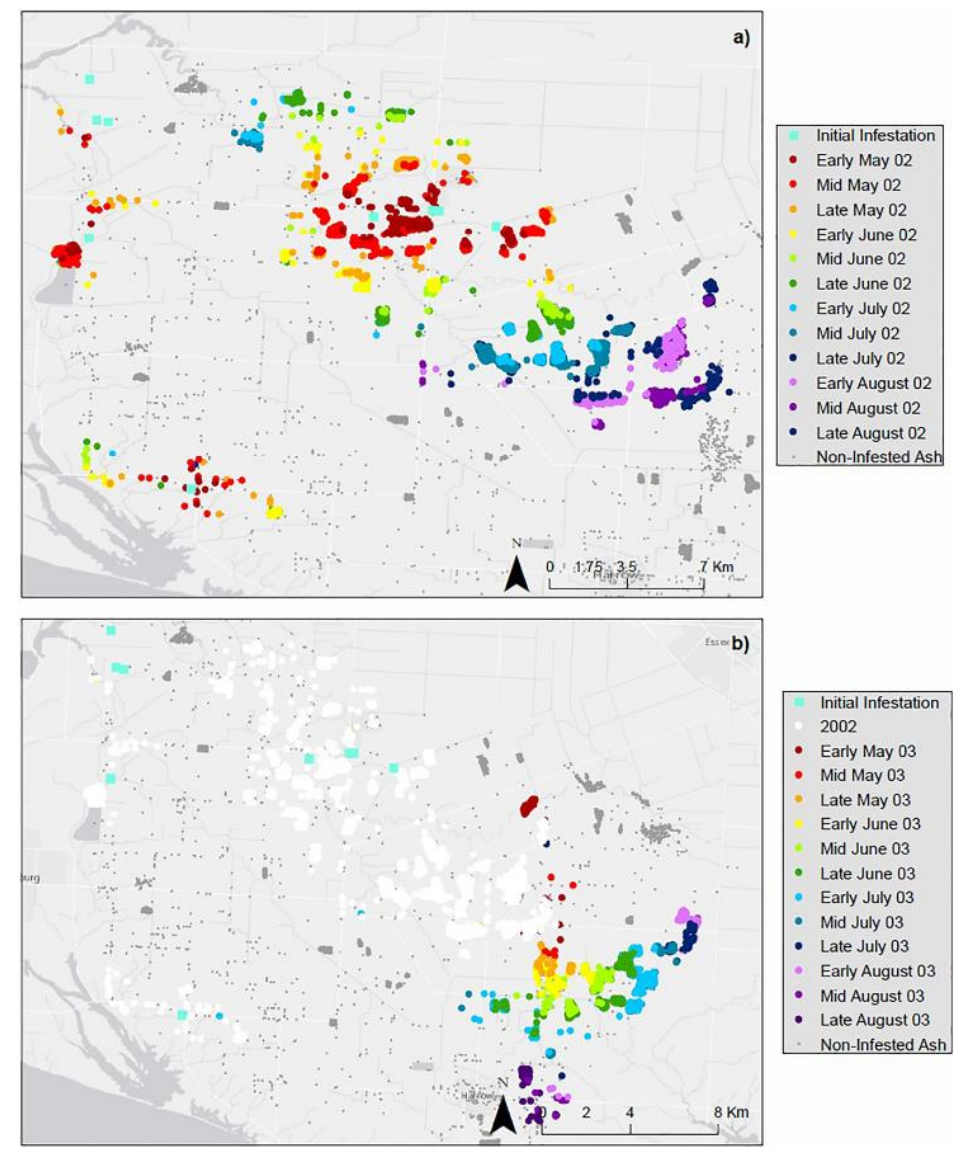

Figure 6. Simulation results of EAB infestation spatial patterns generated for the years (a) 2002 and (b) 2003 for the Rural Landscape Scenario. 


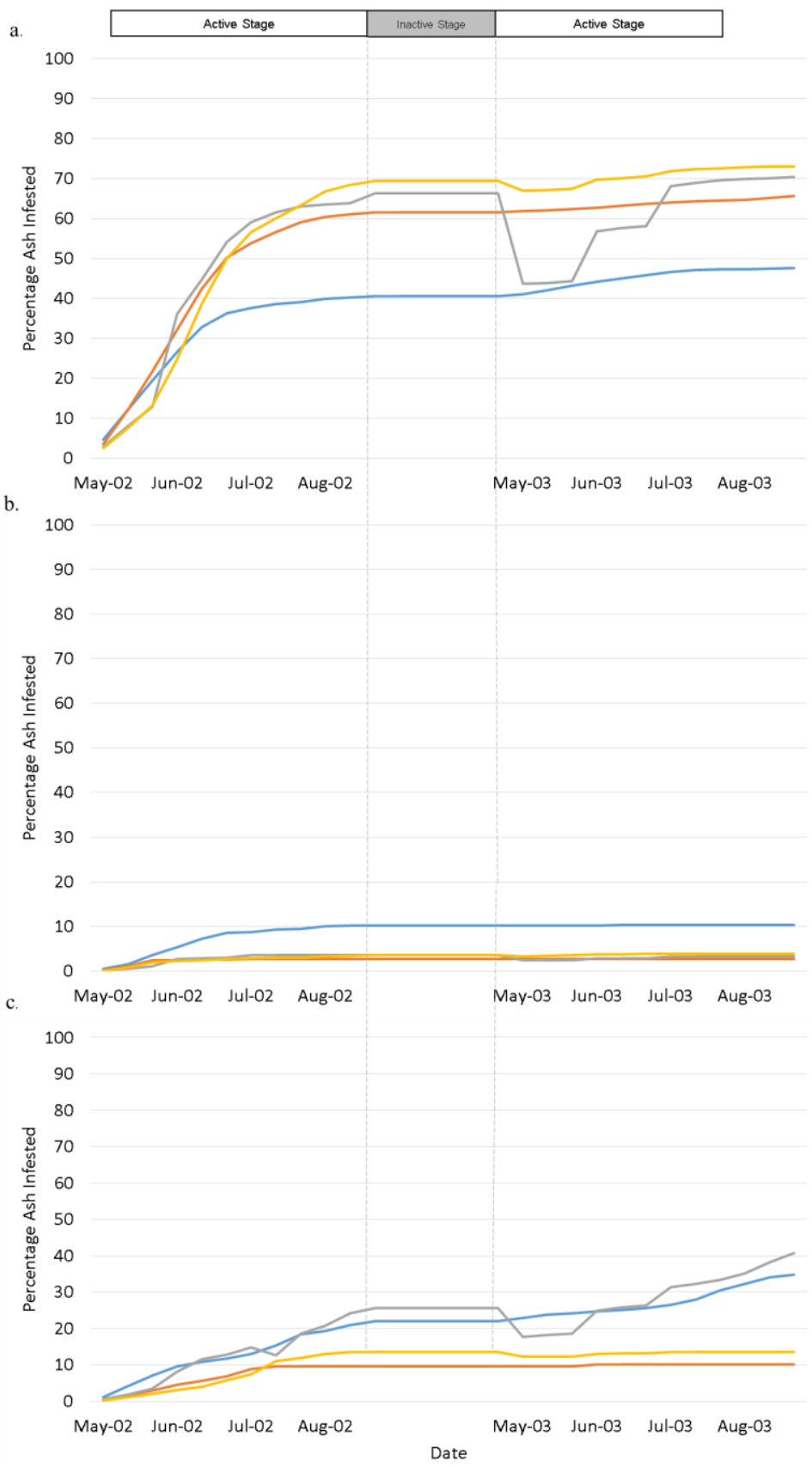

Figure 7. Graphs representing the percentage of all ash trees infested for: (a) Urban Landscape; (b) Rural-Urban Fringe Landscape; and (c) Rural Landscape scenarios.

In contrast, wind constrains EAB spread in the Urban-Rural Fringe Scenario. There were less susceptible trees downwind from initially infested regions and, as such, wind minimized spread. In total, $2.7 \%$ of all ash trees became infested over a period of two years (Figure $7 \mathrm{~b}$ ), a decrease of $7 \%$ in ash infested. Similarly, wind acts as a constraint for the Rural Landscape Scenario with a total of $20.3 \%$ of all ash became infested over a period of two years (Figure 7c), decreasing the percentage of ash that became infested by $14 \%$.

Consistent with the previous set of scenarios, the Urban Landscape Scenario experienced the highest percentage of total infestation, followed by the Rural Landscape Scenario and lastly the Rural-Urban Fringe Scenario. 
Landscape, Wind, and Temperature-The combined effects of wind $\mathcal{E}$ temperature have been incorporated into the simulation. For simplicity reasons, the spatial outputs are only presented for the Urban Landscape Scenario in Figure 8d. The rate of spread for the combined effects of wind and temperature are presented for the Urban Landscape Scenario in Figure 7a, the Urban-Rural Fringe Scenario in Figure 7b, and the Rural Landscape Scenario in Figure 7c. In the model, wind either constrained or accelerated propagation in the landscape. This pattern remains consistent in combination with temperature as a criterion, but also adds variation in response to monthly temperatures. The scenarios, using the combined wind and temperature criteria in the weighted $\mathrm{MCE}$, generated more detailed spatial patterns of spread, where spread was constrained in colder months and enhanced in warmer months and, in addition, captures the northeast direction of infestation propagation on a regional scale, consistent with real world EAB datasets.
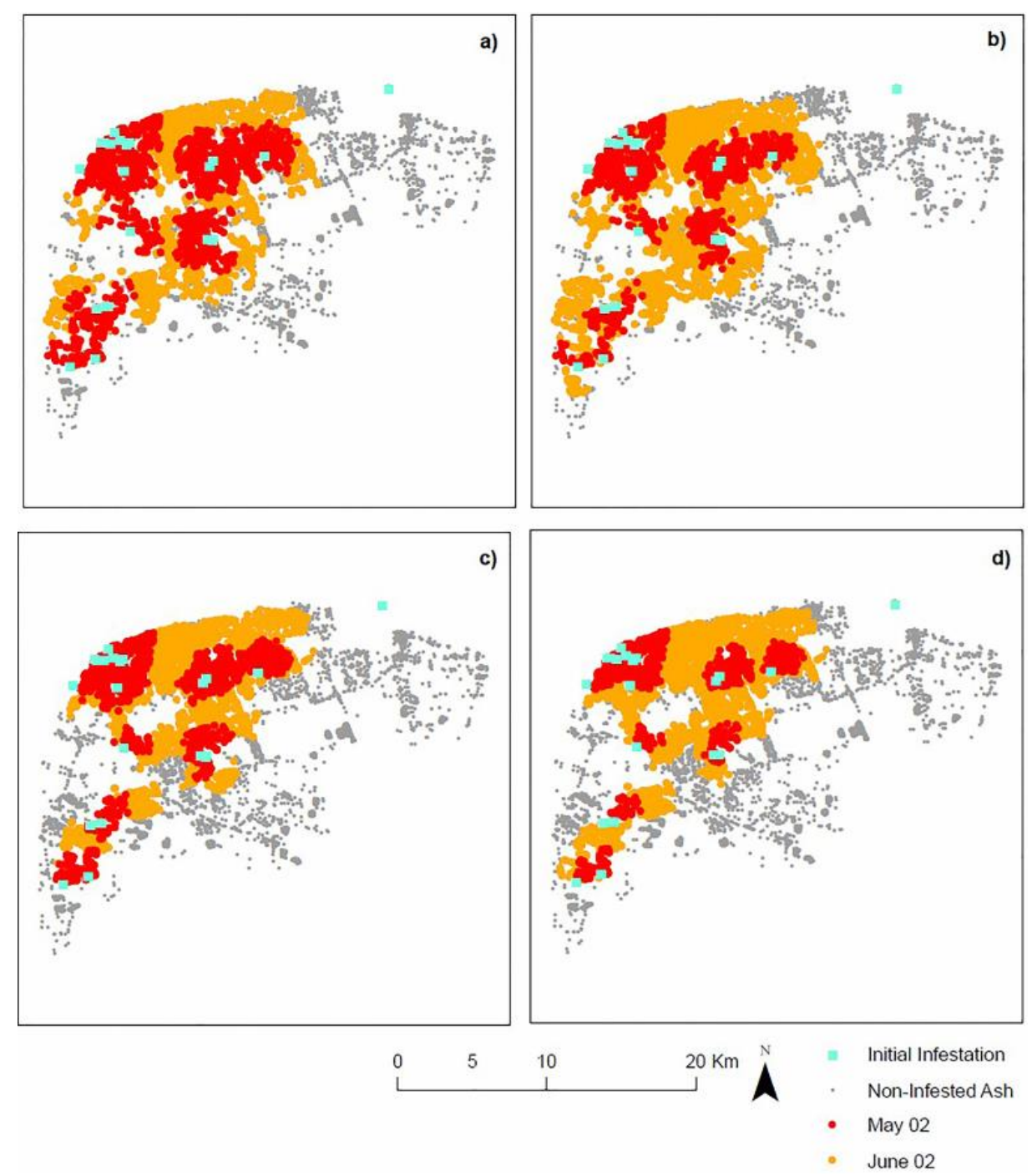

Figure 8. Simulation results generated for May and June 2002 comparing spatial patterns of EAB spread for (a) Urban Landscape Scenario and its changes with (b) temperature (c) wind and (d) combined wind and temperature.

Maintaining consistency with all other scenarios, the Urban Landscape Scenario demonstrated the fastest rate of spread and the highest percentage of infestation with a total of $73.3 \%$ of all ash becoming infested from 2002 to 2003. The simulation results for the Urban-Rural Fringe Scenario indicate the lowest rate of spread and the lowest percentage of infestation with a total of $3.8 \%$ of all ash becoming 
infested by 2003 (Figure 7b). Lastly, the Rural Landscape Scenario patterns of infestation has a total of $13.5 \%$ of all ash in the landscape becoming infested by 2003 , taking both wind and temperature climate criteria into account.

\section{Discussion and Conclusions}

The developed CA-EAB model provides a framework for the representation of EAB infestation as a non-linear, complex system using the cellular automata methodology, an approach not fully explored for this particular invasive species. Non-linearity is represented in the re-calculation of tree susceptibility at every iteration in response to a changing climate, a changing environment, and the propagation of the infestation. The simulation results indicate that patterns of ash tree infestation and rates of spread are influenced by the type of landscape and distribution of susceptible ash trees that the EAB propagates through.

The Urban Landscape Scenario is significantly more susceptible to EAB infestation than in any other landscape. This has been suggested, but not fully explained in other studies $[14,47,52,53]$. The obtained model simulations indicate the increased rate of EAB spread in urban landscapes emerges from the dynamics between $\mathrm{EAB}$ and the combination of properties that characterize the ash trees in the urban forest landscape. These properties are not imposed, but are a function of the use of geospatial data and data collected in the field used to characterize the urban landscape.

The spatial and biological characteristics of the urban landscape provide a more suitable environment for EAB infestation and spread. Specifically, ash trees make up a high percentage of urban forests and are homogeneously distributed, easing any distance or resource-based constraints that might impact EAB propagation. In addition, transportation networks play an important role in the spread of insect infestation and, although present in all landscape scenarios, are more prominent and frequented in urban settings. Additionally, urban environments experiences heat island effects, whereby temperatures in urban regions may be up to 8 to 10 degrees warmer than its surrounding rural counterpart [54]. The average increased temperatures create a more suitable environment for the development of EAB larvae and adult emergence. Most clearly seen in the urban environment, colder temperatures in May result in a decrease in EAB infestation, as emergence of new adult EAB is constrained. In warmer months, the rate of infestation is increased and the percentage of the landscape infested in almost all landscapes in comparison to scenarios without the effects of temperature.

The land bordering Windsor can be characterized by a mosaic of diverse land use types. As presented in the Rural-Urban Fringe Scenario, this region experienced the lowest susceptibility to EAB infestation. The contrast in land use types in the region creates a highly fragmented landscape that affects insect populations by both reducing available habitats for insect species and constraining spread which is limited by dispersal ability to move throughout landscape patches [55]. This emergent behavior in response to land cover is captured by the proposed spatiotemporal model. Additionally, the Rural Landscape Scenario experienced EAB propagation lesser than that of the Urban Landscape Scenario, but greater than that of the Urban Rural Fringe Scenario. This may also be associated with a less fragmented landscape, far less agricultural land use, and better connectivity between forested regions.

The proposed EAB-CA model framework is useful by representing insect infestation from the bottom-up even in representing a phenomenon that lacks empirical data. The model simulates local pest-host dynamics using readily available biological information obtained from field and lab studies that determine which factors influence ash tree susceptibility. These factors which are local and thus variable across space including tree type, tree size, temperature, wind, and ash tree density and distribution either drives or inhibits EAB spread and thus generates that collective behavior of the species. In addition, the choice to incorporate the MCE into the CA helps to overcome issues of uncertainty associated with determining the susceptibility of ash trees to EAB infestation. This methodology contrasts top-down representations, which require extensive datasets determining patterns of spread over time and detailed tree inventories not available. Thus, the proposed EAB-CA molding approach is beneficial in any data scarce environment. 
Although the conceptualization of the model in the absence of real world data is possible, the validation of the model with regards to this particular phenomenon is presently a more challenging endeavor. Validation refers to the agreement between another independent dataset to evaluate the model output. These independent validation datasets, specifically for this study area at an appropriate spatial and temporal resolution required for this model do not exist. Future work in EAB-CA model validation is feasible pending the availability of EAB infestation datasets due to model flexibility with respect to changes in inputs and parameters.

Since bottom-up methodologies tend to focus on the driving factors which influence rates of spread, future work pending data availability may focus testing additional scenarios by incorporating more detailed inputs as new information comes to light. Examples include incorporating additional factors which may influence EAB propagation including sunlight and aspect [56], analysis of the fine differences in temperature at the edge trees versus the inner regions of the forest, and terrain factors through the use of a DEM which may also influence feedbacks and non-linearity in the system, although these factors may be more suitable for finer scales. The robustness of these factors can then be tested using sensitivity analysis to determine the significance of their inclusion and the level of influence on the propagation of EAB infestation.

The development of satellite populations and long distance dispersal of EAB cannot be easily represented using a CA approach due to the neighborhood that is used to apply the transition rules that simulate the propagation of EAB infestation. This is a common problem where the CA approach is challenged in representing mobile objects [29]. The study reveals that allowing for full mobility of $\mathrm{EAB}$ within the geospatial environment could aid in better representing long distance dispersal patterns of EAB infestation as a result of human-mediated transportation, an issue addressed by using an agent-based model [57] as an extension of the proposed EAB-CA modeling.

Overall, the proposed EAB-CA geosimulation methodology that integrates GIS, MCE and CA is very useful, providing the ability to calculate susceptibility of ash trees based on input data and simulate spatiotemporal dynamics of EAB infestation in response to those values, generating larger scale patterns of infestation. The CA-EAB model provides the potential to explore "what-if" scenarios, where scenarios can be implemented in order to better understand how a pattern of spread may react to events such as climate change, forest fire, and management scenarios, and project future trajectories of infestation propagation at regional scale. They demonstrate the potential to use the developed model as a tool to assist decision-makers in evaluating current and costly eradication strategies, fill in knowledge gaps with respect to spatiotemporal dynamics of EAB spread, and assist in future city planning and forest management strategy formation.

Acknowledgments: This study was funded by Natural Sciences and Engineering Research Council (NSERC) of Canada Graduate Scholarship-Masters (CGS-M) awarded to the first author and Discovery Grant awarded to the second author. The datasets were provided by the Canadian Food and Inspection Agency. The authors are thankful to Meg Krawchuk and Tina Semeniuk for providing feedback at an earlier stage of this research and for the feedback from the anonymous reviewers during the revision process.

Author Contributions: Both authors worked on conceptualization and design of the model described in this study. The first author was involved in data acquisition, implementation of the model within GIS software and generation of simulation results. Both authors participated in the writing of the manuscript, but the first author has taken the lead.

Conflicts of Interest: The authors declare no conflict of interest.

\section{References}

1. Latombe, G.; Parrott, L.; Fortin, D. Levels of emergence in individual based models: Coping with scarcity of data and pattern redundancy. Ecol. Model. 2011, 222, 1557-1568. [CrossRef]

2. Liebhold, A. Use and abuse of insect and disease models in forest pest management: Past, present, and future. Sustainable Ecological Systems: Implementing an Ecological Approach to Land Management; Tech.Rep.RM-247. US Department of Agriculture, Forest Service: Morgantown, VA, USA, 1994; pp. 204-210. 
3. Parunak, H.V.D.; Savit, R.; Riolo, R.L. Agent-based modeling vs. equation-based modeling: A case study and users' guide. In Multi-Agent Systems and Agent-Based Simulation; Springer: Paris, France, 1998; pp. 10-25.

4. Fussmann, G.F. Chaotic dynamics in food web systems. In Complex Population Dynamics: Nonlinear Modeling in Ecology, Epidemiology and Genetics; World Scientific Publishing Company: Singapore, 2007; pp. 1-20.

5. Goodchild, M.F.; Glennon, A. Representation and computation of geographic dynamics. In Understanding Dynamics of Geographic Domains; CRC Press: Boca Raton, FL, USA, 2008; pp. 13-30.

6. O'Sullivan, D.; Perry, G.L. Spatial Simulation: Exploring Pattern and Process; John Wiley \& Sons: Auckland, New Zealand, 2013.

7. BenDor, T.K.; Metcalf, S.S.; Fontenot, L.E.; Sangunett, B.; Hannon, B. Modeling the spread of the emerald ash borer. Ecol. Model. 2006, 197, 221-236. [CrossRef]

8. DeSantis, R.D.; Moser, W.K.; Gormanson, D.D.; Bartlett, M.G.; Vermunt, B. Effects of climate on emerald ash borer mortality and the potential for ash survival in North America. Agric. For. Meteorol. 2013, 178, 120-128. [CrossRef]

9. Canadian Food Inspection Agency. Emerald Ash Borer Latest Information. Available online: http://www.inspection.gc.ca/plants/plant-protection/insects/emerald-ash-borer/latest-information/eng/ 1337287614593/1337287715022 (accessed on 26 July 2015).

10. McCullough, D.G.; Poland, T.M.; Anulewicz, A.C.; Cappaert, D. Emerald ash borer (Coleoptera: Buprestidae) attraction to stressed or baited ash trees. Environ. Entomol. 2009, 38, 1668-1679. [CrossRef] [PubMed]

11. Siegert, N.W.; McCullough, D.G.; Liebhold, A.M.; Telewski, F.W. Dendrochronological reconstruction of the epicentre and early spread of emerald ash borer in North America. Divers. Distrib. 2014, 20, 847-858. [CrossRef]

12. McCullough, D.; Roberts, S. Emerald ash borer; Pest Alert NA-PR-07-02. USDA Forest Service State and Private Forestry, Northeastern Area: Newtown Square, PA, USA, 2002.

13. Krcmar-Nozic, E.; Arthur, L.M.; Wilson, B. The Potential Impacts of Exotic Forest Pests in North America: A Synthesis of Research; Pacific Forestry Centre: Saanich, Vic, Canada, 2000.

14. Kovacs, K.F.; Haight, R.G.; McCullough, D.G.; Mercader, R.J.; Siegert, N.W.; Liebhold, A.M. Cost of potential emerald ash borer damage in US communities, 2009-2019. Ecol. Econ. 2010, 69, 569-578. [CrossRef]

15. Aukema, J.E.; McCullough, D.G.; Von Holle, B.; Liebhold, A.M.; Britton, K.; Frankel, S.J. Historical accumulation of nonindigenous forest pests in the continental United States. Bioscience 2010, 60, 886-897. [CrossRef]

16. City of Peterborough. Emerald Ash Borer Management Plan. Available online: http:/ / www.peterborough.ca/Assets/City+Assets/Planning/Documents/Ongoing+Planning+Studies / Emerald+Ash+Borer+Management+Plan.pdf (accessed on 26 July 2015).

17. Burr, S.J.; McCullough, D.G. Condition of green ash (Fraxinus pennsylvanica) overstory and regeneration at three stages of the emerald ash borer invasion wave. Can. J. For. Res. 2014, 44, 768-776. [CrossRef]

18. Muirhead, J.R.; Leung, B.; Overdijk, C.; Kelly, D.W.; Nandakumar, K.; Marchant, K.R.; MacIsaac, H.J. Modelling local and long-distance dispersal of invasive emerald ash borer Agrilus planipennis (Coleoptera) in North America. Divers. Distrib. 2006, 12, 71-79. [CrossRef]

19. Barlow, L.; Cecile, J.; Bauch, C.T.; Anand, M. Modelling interactions between forest pest invasions and human decisions regarding firewood transport restrictions. PLoS ONE 2014, 9, e90511.

20. Vermunt, B.; Cuddington, K.; Sobek-Swant, S.; Crosthwaite, J. Cold temperature and emerald ash borer: Modelling the minimum under-bark temperature of ash trees in Canada. Ecol. Model. 2012, 235, 19-25. [CrossRef]

21. McKenney, D.W.; Pedlar, J.H.; Yemshanov, D.; Barry Lyons, D.; Campbell, K.L.; Lawrence, K. Estimates of the potential cost of emerald ash borer (Agrilus planipennis Fairmaire) in Canadian municipalities. Arboricult. Urban For. 2012, 38, 81-91.

22. Pontius, J.; Martin, M.; Plourde, L.; Hallett, R. Ash decline assessment in emerald ash borer-infested regions: A test of tree-level, hyperspectral technologies. Remote Sens. Environ. 2008, 112, 2665-2676. [CrossRef]

23. San Souci, J.; Hanou, I.; Puchalski, D. High-resolution remote sensing image analysis for early detection and response planning for emerald ash borer. Photogramm. Eng. Remote Sens. 2009, 75, 905-909.

24. Wu, J.; Marceau, D. Modeling complex ecological systems: An introduction. Ecol. Model. 2002, 153, 1-6. [CrossRef] 
25. DeAngelis, D.L.; Mooij, W.M. Individual-based modeling of ecological and evolutionary processes. Annu. Rev. Ecol. Evol. Syst. 2005, 36, 147-168. [CrossRef]

26. Grimm, V.; Railsback, S.F. Individual-Based Modeling and Ecology; Princeton University Press: Princeton, NJ, USA, 2013.

27. Batty, M.; Torrens, P.M. Modelling and prediction in a complex world. Futures 2005, 37, 745-766. [CrossRef]

28. White, R.; Engelen, G. High-resolution integrated modelling of the spatial dynamics of urban and regional systems. Comput. Environ. Urban Syst. 2000, 24, 383-400. [CrossRef]

29. Torrens, P.M.; Benenson, I. Geographic automata systems. Int. J. Geogr. Inf. Sci. 2005, 19, 385-412. [CrossRef]

30. Hogeweg, P. Cellular automata as a paradigm for ecological modeling. Appl. Math. Comput. 1988, 27, 81-100. [CrossRef]

31. Dytham, C. The effect of habitat destruction pattern on species persistence: A cellular model. Oikos 1995, 340-344. [CrossRef]

32. Balzter, H.; Braun, P.W.; Köhler, W. Cellular automata models for vegetation dynamics. Ecol. Model. 1998, 107, 113-125. [CrossRef]

33. Yang, J.; Wang, Z.; Yang, D.; Yang, Q.; Yan, J.; He, M. Ecological risk assessment of genetically modified crops based on cellular automata modeling. Biotechnol. Adv. 2009, 27, 1132-1136. [CrossRef] [PubMed]

34. Dragicevic, S. Modeling the dynamics of coplex systems using cellular, fuzzy sets and GIS: Invasive species propagation. Geogr. Compass 2010, 4, 599-615. [CrossRef]

35. Bone, C.; Dragicevic, S.; Roberts, A. A fuzzy-constrained cellular automata model of forest insect infestations. Ecol. Model. 2006, 192, 107-125. [CrossRef]

36. Perez, L.; Dragicevic, S. Landscape-level simulation of forest insect disturbance: Coupling swarm intelligent agents with GIS-based cellular automata model. Ecol. Model. 2012, 231, 53-64. [CrossRef]

37. Mathey, A.; Krcmar, E.; Dragicevic, S.; Vertinsky, I. An object-oriented cellular automata model for forest planning problems. Ecol. Model. 2008, 212, 359-371. [CrossRef]

38. Perez, L.; Dragicevic, S. Modeling mountain pine beetle infestation with an agent-based approach at two spatial scales. Environ. Model. Softw. 2010, 25, 223-236. [CrossRef]

39. Land Information Ontario. Ontario Land Use Dataset. Available online: https://www.ontario.ca/page/ land-information-ontario/ (accessed on 26 July 2015).

40. Government of Canada. Temperatures Dataset. Available online: http://climate.weather.gc.ca (accessed on 26 July 2015).

41. Prasad, A.M.; Iverson, L.R.; Peters, M.P.; Bossenbroek, J.M.; Matthews, S.N.; Sydnor, T.D.; Schwartz, M.W. Modeling the invasive emerald ash borer risk of spread using a spatially explicit cellular model. Landsc. Ecol. 2010, 25, 353-369. [CrossRef]

42. Mercader, R.J.; Siegert, N.W.; Liebhold, A.M.; McCullough, D.G. Simulating the effectiveness of three potential management options to slow the spread of emerald ash borer (Agrilus planipennis) populations in localized outlier sites. Can. J. For. Res. 2011, 41, 254-264. [CrossRef]

43. Robertson \& Andow. Human-Mediated Dispersal of Emerald Ash Borer: Significance of the Firewood Pathway. Available online: http://www.entomology.umn.edu/prod/groups/ cfans/@pub/@cfans/@ento/documents/asset/cfans_asset_139871.pdf (accessed on 27 October 2014).

44. Buck, J.; Marshall, J. Hitchhiking as a secondary dispersal pathway for emerald ash borer, Agrilus planipennis. Gt Lakes Entomol. 2008, 41, 197-199.

45. Ryall, K.L.; Silk, P.J.; Mayo, P.; Crook, D.; Khrimian, A.; Cossé, A.A.; Sweeney, J.; Scarr, T. Attraction of Agrilus planipennis (Coleoptera: Buprestidae) to a volatile pheromone: Effects of release rate, host volatile, and trap placement. Environ. Entomol. 2012, 41, 648-656. [CrossRef] [PubMed]

46. Pasek, J.E. 30. Influence of wind and windbreaks on local dispersal of insects. Agric. Ecosyst. Environ. 1988, 22, 539-554. [CrossRef]

47. Huset, R. A GIS-based Analysis of the Environmental Predictors of Dispersal of the Emerald Ash Borer in New York. Master's Thesis, Syracuse University, Syracuse, NY, USA, May 2013.

48. Straw, N.A.; Williams, D.T.; Kulinich, O.; Gninenko, Y.I. Distribution, impact and rate of spread of emerald ash borer Agrilus planipennis (Coleoptera: Buprestidae) in the Moscow region of Russia. Forestry 2013, 86, 515-522. [CrossRef]

49. Saaty, T. The Analytic Hierarchy Process; McGraw-Hill: New York, NY, USA, 1980. 
50. Environmental Systems Research Institute. ArcGIS Desktop: Release 10.1; Environmental Systems Research Institute: Redlands, CA, USA, 2015.

51. Eastman, J. IDRISI Selva; Clark University: Worchester, MA, USA, 2012.

52. MacFarlane, D.W.; Meyer, S.P. Characteristics and distribution of potential ash tree hosts for emerald ash borer. For. Ecol. Manag. 2005, 213, 15-24. [CrossRef]

53. Poland, T.M.; McCullough, D.G. Emerald ash borer: Invasion of the urban forest and the threat to North America's ash resource. J. For. 2006, 104, 118-124.

54. Davidson, A. Summer in the City: NASA Turns Technology toward the Earth To Determine What, Exactly, Makes Cities so Hot. Atrodams. 1998. Available online: http://www.metropolismag.com/ new/content/tech/aug98sum.htm (accessed on 20 August 2014).

55. Tscharntke, T.; Brandl, R. Plant-insect interactions in fragmented landscapes. Annu. Rev. Entomol. 2004, 49, 405-430. [CrossRef] [PubMed]

56. Wang, X.Y.; Yang, Z.Q.; Gould, J.R.; Zhang, Y.N.; Liu, G.J.; Liu, E.S. The biology and ecology of the emerald ash borer, Agrilus planipennis, in China. J. Insect Sci. 2010, 10. [CrossRef] [PubMed]

57. Anderson, T.; Dragicevic, S. An agent-based modeling approach to represent infestation dynamics of the emerald ash borer beetle. Ecol. Inform. 2015, 30, 97-109. [CrossRef]

(C) 2016 by the authors; licensee MDPI, Basel, Switzerland. This article is an open access article distributed under the terms and conditions of the Creative Commons by Attribution (CC-BY) license (http://creativecommons.org/licenses/by/4.0/). 